\title{
1 Allergenicity of bony and cartilaginous fish - molecular and 2 immunological properties
}

3

4

5

6

7

8

\section{Abstract:}

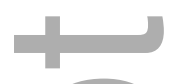

Allergy to bony fish is common and probably increasing worldwide. The major heat stable panfish allergen, parvalbumin (PV), has been identified and characterized for numerous fish species. In contrast, there are very few reports of allergic reactions to cartilaginous fish despite widespread consumption. The molecular basis for this seemingly low clinical cross-reactivity between these two fish groups has not been elucidated. PV consists of two distinct protein lineages, $\alpha$ and $\beta$. The $\alpha$-lineage of this protein is predominant in muscle tissue of cartilaginous fish (Chondrichthyes), while $\beta$-PV is abundant in muscle tissue of bony fish (Osteichthyes). The low incidence of allergic reactions to ingested rays and sharks is likely due to the lack of molecular similarity, resulting in reduced immunological cross-reactivity between the two PV lineages. Structurally and physiologically both protein lineages are very similar, however the amino acid homology is very low with $47 \%$ to $54 \%$. Furthermore, PV from ancient fish species such as the coelacanth demonstrates $62 \%$ sequence homology to leopard shark $\alpha$-PV and $70 \%$ to carp $\beta-P V$. This indicates the extent of conservation of the PV isoforms lineages across millennia. This review highlights prevalence data on fish allergy and sensitization to fish, and details the molecular diversity of the two protein lineages of the major fish allergen PV among different fish groups, emphasizing the immunological and clinical differences in allergenicity.

\section{Introduction:}

Allergy to seafood is common, potentially life threatening, often lifelong and accounts for up to $5 \%$ of food allergies in children and $2 \%$ of food allergy in adults worldwide $[1,2]$. There are major regional differences, with apparent much higher rates of sensitization to fish in Asia. The move towards healthy lifestyles and eating habits has seen a steady increase in the consumption of fish, which suggests that seafood allergy will continue to be a major health This is the author manuscript accepted for publication and has undergone full peer review but has not been through the copyediting, typesetting, pagination and proofreading process, which may lead to differences between this version and the Version of Record. Please cite this article as doi: $\underline{10.1111 / \text { cea. } 12892}$

This article is protected by copyright. All rights reserved 
issue into the foreseeable future. Recent research has focused on the molecular characterization of seafood proteins for identification of major allergens and for improved diagnostics. The major allergen identified in fish, parvalbumin (PV), binds calcium, is heat stable and is involved in the muscle relaxation and contraction cycle [3] as well as signal transduction [4]. PV is reported to account for up to $90 \%$ of cross-reactive allergic immunological reactions to fish

\section{Fish allergy epidemiology: How common is it?}

Allergic reactions to bony fish are well documented. However, the true prevalence of fish allergy is unknown, with a lack of high quality population based data. Reported prevalence ranges from self-reported rates of $5 \%$ to challenge proven rates of $0.1 \%$. Most estimates are based upon small samples, patient-based questionnaires or allergic cohorts from specialist centers. From current available data is appears that there are significant regional differences in rates of bony fish allergy (see Table 1). It is likely that prevalence of fish allergies is diet (and exposure) related, with higher reported rates of bony fish allergy in regions with high consumption [6].

Asia has one of the largest populations of fish consumers with reported yearly consumption rates significantly above the world average rate of $16 \mathrm{~kg}$ per capita with up to $54 \mathrm{~kg}$ per capita in Japan (2011) [7]. A review of seafood allergy in South East Asia reported a higher rate of fish allergy in the Philippines ( $n=11,434 ; 2.29 \%)$ compared to Singapore $(n=6,498 ; 0.26 \%)$ and 
Thailand ( $n=2,034 ; 0.29 \%$ ) [8]. Fish, shrimp and crab were amongst the leading 5 causes of food

57 allergy in Thai preschool children, and fish allergy was estimated to account for $13.2 \%$ of food allergy in a cohort of food allergic children in Singapore [9]. As a cause of food-related anaphylaxis fish and shellfish accounted $3.3 \%$ and $66.7 \%$, respectively in a small cohort in Singapore [10]. Similarly, fish allergy was reported to account for $4.1 \%$ of IgE-mediated food allergy in adults attending for care of their food allergy in Singapore [11].

While prevalent across Asia, fish allergy also appears to be relatively common in Europe (Table 1), again with significant sub-regional variation. Self-reported prevalence of fish allergy is as high as $3 \%$ [12], while the incidence of challenge proven fish allergy challenge is reported to be only $0.1 \%$ [13]. Across European cities, approximately $0.2 \%$ of the population is reported to be allergic to some type of fish [14].The populations of Portugal, Spain and Scandinavian are likely to be the highest consumers of fish in Europe [15] and the highest rates of fish allergy are also generally reported in Northern Europe [16]. In a Norwegian prospective observational cohort of 3,623 children [12]- 3\% were reported to have fish allergy by 2 years of age. Early onset of fish allergy was also described in a cohort of Spanish food allergic children who had allergy to cod, tuna, hake and whiff predominantly before the age of 2 years [17].

In Australia, $5.6 \%$ of a large cohort of food allergic children were identified as having fish allergy, with the most commonly implicated fish being tuna, salmon, barramundi and flathead [18]. Of those with a fish allergy, $20 \%$ had a history of fish-related anaphylaxis. Clinical and allergy skin test (SPT) cross-sensitivity between the fish species was also common within this fish allergic cohort, with $93 \%$ being atopic to at least one other fish type on SPT and $29 \%$ with a previous clinical allergic reaction to another species of fish. In a separate Australian cohort study $(n=94)$ of children with proven seafood allergy, $64 \%$ of the cohort were allergic to fish [19], with 'White fish', salmon and tuna being most commonly implicated species and allergic reactions to basa [catfish], barramundi, bream, and cod all reported.

In the USA, $0.4 \%$ of the population was estimated to be fish allergic and $2 \%$ shellfish allergic based upon a large national random telephone survey [20]. The self-reported major allergenic fish species included salmon, tuna and cod. A similar random telephone survey was conducted across Canada in 2002 and estimated the population prevalence of fish allergy to be $0.1 \%$ [21] 
with the most common fish allergens being cod and salmon. Similarly, a US self-report survey found a prevalence of $0.7 \%$ and $0.6 \%$ for self-reported and self-reported doctor-diagnosed fish allergy, respectively [22].

\section{Classification of cartilaginous and bony fish}

In order to understand the clinical, diagnostic and allergen characterization implications of differences between various fish, it is useful to review taxonomy and evolution of fish. Biologically, fish are divided into two classes, Chondrichthyes (cartilaginous fish) and Osteichthyes (bony fish). Bony fish are the largest group of all vertebrates consisting of 45 orders and over 435 families. Bony fish possess stable cranial bones, swim bladders and, in certain species, even primitive lungs. Bony fish can be further divided into ray finned fish (Actinopterygii) and lobe-finned fish (Sacropterygii). Actinopterygii is the biggest class and possess fins made of webs of skin supported by bony spines and includes all edible fish. Sacropterygii consists of fish with fleshy, lobed, paired fins, which are joined to the body by a single bone. The West Indian Ocean coelacanth discussed in this review is the oldest, extant lineage of Sacropterygii with evidence of continuous presence for 100 million years.

The Chondrichthyes (cartilaginous fish) in contrast are jawed fish with skeletons made of cartilage. They can be further divided into two subclasses - Elasmobranchii and Holocephali. Elasmobranchii consists of sharks (Selachii) and rays and skates (Batoidea). Lack of swim bladders, rigid dorsal fins, small placoid scales and five to seven pairs of gill cleft openings to the exterior are characteristic of the Elasmobranchii. In contrast, the subclass Holocephali consists of only one surviving Chimaeriformes order, which constitutes rat fish, rabbit fish and elephant fish. They are bottom dwellers, having simplified guts where the stomach is merged with the intestine. An interesting species of study is the chimaeric elephant or Australian ghost shark [Callorhinchus milli], as it is closely related to sharks but also have distinct features similar to bony fish, such as gill covers.

\section{Fish Allergens}

\section{$\underline{4.1 \text { Parvalbumin }}$}


113 Isoforms: The major pan-fish allergen, parvalbumin (PV), belongs to the EF-hand helix-loop114 helix domain family of calcium binding proteins and constitutes the biggest group of animal 115 derived food allergens [23]. It has been characterized in detail from 12 fish species (registered with the IUIS) across various continents including Europe and the USA $[1,9,14,20]$ and is 117 reported to account for up to $90 \%$ of cross-reactive fish allergy $[2,24]$. PV is abundant in muscle and nerve tissue of lower vertebrates and is capable of binding $\mathrm{Ca}^{2+}$ and $\mathrm{Mg}^{2+}$. Two distinct phylogenetic lineages of PV, $\alpha$ and $\beta$, have been identified, with the $\beta$ isoform seems to be predominant in muscle tissue of bony fish $[25,26]$. The characteristics of PV from bony and cartilaginous fish [ $\alpha$ isoform] along with their isoforms, molecular weights and isoelectric points are listed in ascending order of discovery in Table 2.

Chemistry: PV is an acidic, sarcoplasmic, 10 - $15 \mathrm{kDa}$ protein that is extremely resistant to heat [27], proteolytic and chemical degradation [28, 29]. It was first identified as an allergen in Baltic cod (Gadus morhua) in 1969 and named Gad c 1 or Allergen M [29]. The isoelectric points range from $3.9-4.5$ for the $\beta-P V s$, whereas it is generally above 5.0 for different $\alpha-P V s$ [30].

PV's are globular in shape and contain six $\alpha$-helices (A, B, C, D, E, and F). These helices form three helix-loop-helix EF hand motifs $(A B, C D$ and $E F)$. The heat stability and resistance to protease degradation is attributed to chelated calcium which changes the conformation of PV [31]. As a consequence of conformational changes, the allergenicity of PV is also higher in the presence of calcium due to better exposure of IgE binding epitopes [2, 32]. The calcium-binding epitopes in PV are well conserved across bony and cartilaginous fish (Figure $1 \mathrm{~A}$ and 1B), demonstrating the similar functionality of this protein.

Characterization: PV has been extensively studied in bony fish including in Atlantic cod (Gadus morhua) [28, 29, 33-37], Alaska Pollack (Theragra chalcogramma) [38, 39], common carp 136 (Cyprinus carpio) [24, 30, 37, 40, 41], silver carp (Hypophthalmichthy molitrix) [42], Atlantic salmon (Salmo salar) [39, 43-47] and recently Asian seabass (Lates calcarifer) [48, 49]. In comparison, studies on PV from cartilaginous fish are limited to leopard shark [25], red stingray [26], Atlantic stingray [50] and thornback ray [51]. $\beta$-parvalbumin is more abundant in bony fish 
and appears to be responsible for the majority of allergic reactions, while the $\alpha$ isoform seems to be predominant in cartilaginous fish $[25,26]$. Some fish species seem also to express multiple isoforms of $\beta$-PV such as $\beta 1$ and $\beta 2$ seen in barramundi and isoforms 1 to 9 in zebrafish $[48,52]$.

Differences between $\alpha$ - and $\beta$-PV: There appears to be low clinical cross-reactivity between $\alpha$ and $\beta$-PV of the two fish classes (bony and cartilaginous) as evident from the lack of detailed published reports of individuals being allergic to both [53-55]; however the reasons for this low cross reactivity are poorly understood. One of the key differences between the lineages is the presence of more acidic amino acid residues with pl 4.5 or lower in $\beta$-PV, while $\alpha$-PV consists of less acidic amino acid residues with pl 5.0 or higher [26]. The $\alpha$ and $\beta$ lineages also differ slightly in length, with $\alpha-P V$ usually consisting of 109 or more amino acids while $\beta$-PV generally have 108 or fewer amino acids [31]. This extensive molecular variation may be the key to understanding why the $\alpha$-PV predominant fish are less allergenic and the limited clinical crossreactivity observed between different fish species and groups.

Leopard shark $\alpha$-PV was the first shark PV to have its crystal structure studied [25]. The amino acid sequence homology of PV from one shark and several bony fish [carp, cod, salmon] is less than 50\% (Table 3). Interestingly, bony fish PV's demonstrate relatively high sequence identity with muscle from amphibians (63-76\%), reptiles (56-69\%) and birds (54-71\%), whereas human muscles are devoid of $\beta$-PV with only $56 \%$ sequence homology between human $\alpha$-PV and fish $\beta$ PV. The homological distance is an indicator of the differential allergenicity of the two isoform lineages [56], with evolutionary divergence of $\alpha$ and $\beta-P V$ lineages in vertebrates (Figure 2). Interestingly, PV amino acid sequences $(\alpha$ and $\beta$ ) for the West Indian Ocean coelacanth (UniProtKB ID: P02629.1 and UniProtKB ID: P02623.1) have high amino acid identity (62\% and 70\%) to leopard shark $\alpha$-PV but also carp $\beta$-PV, respectively (Table 3 ). Here, the degree of sequence identity is a good indicator of the extent of molecular conservation of PV across a vast time period.

\section{$\underline{4.2 \text { IgE binding epitopes and clinical cross-reactivity }}$}


167 Elucidation of the PV IgE binding epitopes is necessary to understand allergen-antibody interactions which result in clinical reactivity. IgE binding epitopes of PV from five fish, Atlantic $\operatorname{cod}($ Gad $m$ 1), Baltic cod (Gad c 1), common carp (Cyp c 1), chub mackerel (Sco j 1) and Atlantic salmon (Sal s 1), have been elucidated in detail (Figure 3A). Epitopes for Atlantic cod, Atlantic salmon and chub mackerel have been individually mapped using overlapping peptides of PV and analyzed using allergic patient's serum $\lg E[44,57,58]$. The epitopes for Baltic cod were elucidated via mutated derivatives of PV and immunological reactivity of overlapping tryptic peptides [34]. Carp PV epitopes have been identified using patient sera by screening against a decamer phage library, computational matching and alignment techniques [32]. While PV from Atlantic cod, Baltic cod, common carp, chub mackerel and Atlantic salmon differs in amino acid sequences, they seem to share some of the linear antibody binding epitopes. Currently there is very little information available about conformational IgE binding epitopes, but it is very likely that they are very different from each other. A comparative study by Kobayashi et al [59] demonstrated the importance of stereoscopic conformation for IgE binding in a range of different PVs, with a structural dependence on Ca2+ binding.

\section{(n)}

Fish allergic patients generate a variety of epitope specific IgE which have been used in epitope mapping for five fish species including cod, salmon, carp and mackerel. In Gad c1 (cod) there are five regions reported to include IgE-binding epitopes; residues 13-32 in the AB domain, 3344 on the region joining the $A B$ and $C D$ domains, 49-64 in the calcium-binding region in the $C D$ domain, 65-74 in the region joining $C D$ and EF domains and the 88-96 calcium binding region in the EF domain [34]. Three additional epitopes were later identified by mapping mimotopes onto the molecular surface of natural carp PV via a surface-matching algorithm [32]. While two epitopes were found within regions joining the domains $A B$ and $C D$, and $C D$ and $E F$, the third epitope was found in the calcium-binding loop of the EF domain. The carp $\beta-P V$ model has been used to specify the known IgE binding epitopes (Figure 3B). Epitope alignment has shown that region IV is highly antigenic, while region I seems to be more species-specific (which is implicated especially in the case of clinical mono-sensitivity to salmon) and perhaps several species in the group of salmonidae [1]. 
197 Collagen, vitellogenin, fructose bisphosphate-aldolase and beta-enolase $[45,60-65]$ have been reported as potentially important allergens in fish. The first instance of collagen as a putative fish allergen was reported in bigeye tuna [66] where collagen was shown to elicit IgE-reactivity in five of eight tuna-allergic patients. Here, an inhibition ELISA [enzyme linked immunosorbent assay] strongly implicated the allergenicity of collagen being independent of fish species. Additionally, the importance of collagen as a pan-allergen has been demonstrated recently [67,

203 68]. In a cohort of 36 Japanese fish (raw and cooked) allergic patients, 50\% were found to have 204 IgE to mackerel collagen. Allergenicity of fish collagen from cartilaginous fish has recently been 205 demonstrated to be lower than that of bony fish collagen [67]. In a separate study, $\alpha$ and $\beta$ chain collagen (120 and $240 \mathrm{kDa}$, respectively) were identified as allergens in two species of tuna [albacore and yellowfin] [69]. The hormone vitellogenin, from Beluga caviar and salmon roe, has been shown to cause IgE-reactivity $[45,65]$. Fish allergic patients have also been 209 reported to produce IgE to fish gelatin, a type I collagen [62], which has been reported to cause anaphylaxis [64].

Fish contaminated with the parasitic nematode, Anisakis, may cause allergic reactions, where $212 \lg \mathrm{E}$ is directed not at fish allergen, but at parasite proteins. These reactions can be 213 misdiagnosed as fish allergy [70-74]. A number of allergens have been characterized from Anisakis including tropomyosin and protease inhibitors. Occupational allergy due to inhalation of heat stable parasite allergens has also been shown to cause allergic reactions in fish processing workers $[75,76]$.

\section{Changes in allergenicity related to exposure}

Oral ingestion of fish allergens is the primary route of exposure and in sensitized individuals may result in IgE-mediated immune responses due to the allergen being absorbed via the 221 mucosa of the gastrointestinal tract [77]. Absorption of allergen across mucosa can be rapid 222 and codfish proteins have been identified in the sera of healthy individual within 10 minutes of 223 consumption. Here the biological activity of the allergens was lost at pH 2.0, but at pH 3.0 the 
224 protein patterns and histamine releasing capacity of the proteins were maintained up to 2 225 hours post digestion. The increased $\mathrm{pH}$ was a result of antacid medication leading to 226 incomplete digestion and rapid uptake of the allergens.

227

Determining true clinical cross sensitivity between fish species in fish allergic individuals is problematic, particularly when using current standard IgE testing. In vitro or SPT cross reactivity is not always predictive of in vivo cross sensitization and actual clinical allergy. In South Africa, a study of 10 fish allergic patients using five commonly consumed fish, pilchard, anchovy, hake, snoek, and yellowtail, reported pilchard PV as being the major cross-reactive allergen using different in vitro tests [78]. Serum from 10 fish allergic patients in Norway demonstrated crossreactivity amongst 9 different commonly consumed fish species [39]. Those individuals sensitive to cod were also sensitized to salmon, whereas Halibut, flounder, tuna and mackerel were found to be the least cross-reactive. A Japanese study of 43 fish species, consisting of both bony and cartilaginous fish, used sera from 38 fish allergic patients and, utilizing radioallergosorbent test (RAST), reported low IgE reactivity to smoothhounds, spotted smoothhounds, blue sharks and salmon sharks [46]. Halibut was also shown to have low IgE reactivity, whereas, whiting, mackerel, saurel, Japanese sardine, silver salmon and bigeye tuna, all commonly consumed fish in Japan, were reported to have high IgE-reactivity within this cohort. In a single case of anaphylaxis to dogfish, (a type of shark), the patient was tolerant to horse mackerel, hake, rays and mollusks [79]. A $14 \mathrm{kDa}$ protein was detected although the biochemical, immunological properties and lineage of the allergen was not confirmed. This may be explained by the fact that Chondrichthyes are likely to have low levels of expression of

247 allergenic fast muscle switching $\beta-P V$ and more non-allergenic $\alpha-P V$ above $[27,80]$. the fact that they are commonly consumed. Although not from fish, in a single case of near fatal anaphylaxis to frog's legs [81], the causative allergen was identified as $\alpha-P V$. In a separate 
251 study, 15 fish allergic patients also cross-reacted, in vitro, to PV from frog [82]. While cross252 reactions to both $\alpha$ and $\beta$-PV were observed, $\beta$-PV demonstrated significantly more IgE-binding 253 than $\alpha$-PV in serum from 11 fish allergic patients. With $60-70 \%$ amino acid homology between 254 bony fish $\beta$-PV and frog $\beta$-PV, this potentially explains the high degree of cross-reactivity 255 between the two proteins [82]. In comparison, only 45-54\% amino acid identity was seen 256 between $\alpha-P V$ from frog and fish PV.

257 In a Japanese cohort (with fish-allergy based upon questionnaire) [68], PV and collagen were 258 identified as highly cross-reactive fish pan-allergens and causative factors of fish allergy [83]. 259 Sera from 16 patients with fish parvalbumin or collagen allergy were used to analyze IgE 260 reactivities and cross-reactivities using ELISA and inhibition ELISA in 26 fish species. IgE reactivities of extracts from 22 species were extensively variable as determined by ELISA using 262 sera obtained from patients with fish PV specific allergies. These patients showed little to no reactivity to mackerel and salmon extracts whereas all patients with fish collagen-specific 264 allergies indicated IgE cross-reactivity to 22 types of fish. Collagen specific allergic patients strongly reacted to rainbow trout, Atlantic salmon, skipjack, and bigeye tuna extracts. In contrast, patients with fish parvalbumin-specific allergies reacted weakly to the same fish species. Fish collagen was indicative of a panallergen, in addition PV, when all 26 species of fish were found to be cross-reactive with Pacific mackerel collagen.

\subsection{Occupational exposure}

270 Workplace related fish allergies are of major concern. Inhalation of aerosolized allergens is the 271 common exposure route, as reported previously in large occupational and industrial processing 272 venues [60, 84-87]. Anaphylaxis is rare, but dermatitis and respiratory conditions have been 273 commonly observed upon inhalation of aerosolized allergens [73]. Although occupational 274 allergy has also been extensively studied in several countries [6, 85, 86, 88-94], there are very 275 few reports of the specific proteins, which drive this occupational fish sensitization.

276 Two separate case reports of fatal occupational asthma in adult males have been attributed to 277 "dust" inhalation from powdered shark cartilage [54, 55]. Shark cartilage dust has also been 
278 implicated as an asthma inducing agent in the USA [55] [54]. In these reports, the specific 279 causative allergens were not identified, but shark cartilage has been shown to contain several 280 proteins, including collagen.

281 As little as $30 \mathrm{ng} / \mathrm{m}^{3}$ of aerosolized fish antigen is reported to cause allergic asthmatic reactions 282 [91]. In a study of workplace exposure to saltwater bony fish (pilchard and anchovy), 7\% of 283 workers reported allergic symptoms - including $2.6 \%$ with occupational allergic rhinoconjunctivitis and $1.8 \%$ with asthma [86]. In a salmon processing plant where workers were exposed to up to $75 \mathrm{ng} / \mathrm{m}^{3}$ of aerosolized allergen Sal s 1 [85], 50\% of workers developed respiratory symptoms after commencement of employment.

\section{Diagnosis of fish allergy}

289 The exact identity of the type/species of fish consumed by individuals experiencing fish allergy 290 is often unknown and as a result, it is often difficult to determine which specific fish allergen/s 291 are responsible for the allergy in any individual fish allergic patient. In vivo skin prick testing 292 (SPT) is an inexpensive, rapid and relatively safe means of screening patients with IgE-mediated 293 fish allergy. One limitation of this technique is the possibility of clinically irrelevant in vivo 294 cross-sensitization to other fish allergens, resulting in false-positive results- especially in 295 patients with poor clinical history [95]. Additionally for many fish species, particularly outside 296 Europe, there are no commercial SPT preparations available, so clinicians are reliant on fresh 297 prick-to-prick testing using the candidate raw fresh fish.

Likewise, serum specific IgE (sslgE) and other qualitative in vitro assays are also good indicators of IgE-sensitization, but their presence does not necessarily correlate with clinical reactivity. For a few fish species, positive predictive values (PPV) for clinical reactivity are available, such that individuals with a very high sslgE above the 95\% PPV can be relatively confidently diagnosed as being allergic to this specific food. In general however, the negative predictive value of fish sslgE, and the ability to distinguish clinical reactivity and sensitization with levels below the $95 \%$ PPV is, poor. For cod fish allergy, IgE levels of $20 \mathrm{kU} / \mathrm{I}$ [ $>95 \%$ confidence] have been used to 305 predict clinical reactivity. 
The amount of fish ingested may be important for some individuals with fish allergy. Moreover important fish pan-allergens may vary in concentration between fish. However, information on threshold doses and lowest observed adverse effect level (LOAEL) values for triggering of fish related allergic reactions is limited. The fish ED10 based upon data from the EuroPrevall cohort [eliciting dose to which $10 \%$ of an allergic population would be expected to first clinically react] is estimated to be $27 \mathrm{mg}$ [96]. A LOAEL of $5 \mathrm{mg}$ for herring or cod was estimated as the lowest dose of fish required to elicit a clinical response, using results of DBPCFC from 14 fish allergic patients [97]. Other factors may influence thresholds, such as impaired gastric digestion. Codfish proteins digested in hypo-acidic conditions $(\mathrm{pH} 3.0)$ were demonstrated to reduce the tolerance levels between 10 to 30 times as compared to digestion at pH 2.0. Lower dosage levels of less than $3 \mathrm{mg}$ were demonstrated to trigger allergic reactions [77].

A study from South Africa highlighted the importance of food challenges in diagnosis of fish allergy by using DBPCFC to confirm or refute suspected species-specific fish allergy [98]. In a cohort of 105 patients with perceived or a clinical history of fish allergy, reported allergy was most common to hake (24\%), yellowtail $(21.9 \%)$, salmon $(15.2 \%)$ and mackerel $(15.2 \%)$. The patients were subject to SPTs and DBPCFCs; sslgE and Western blots were performed. Speciesspecific IgE-mediated fish allergy was confirmed in one patient and refuted in six patients by food challenge.

Avoidance of the causative food is the primary means of management of food allergy. Accurate and extensive labeling of food and conscientious reading of labels is important to prevent ingestion of allergens. Accidental ingestion is still relatively common due to factors such as misleading labels, cross-contamination during processing and preparation equipment processing different foods or unknown allergens hidden in foods. A decision tree has been suggested to manage fish allergy in a stringent manner that also takes into account adverse parasitic and toxin reactions [1].

A recent review highlights the progression of detecting and quantifying allergens in food products, including fish, using mass spectroscopy (MS) [99]. Antibody based methods, such as ELISA, currently used for the detection and quantification have their limitations, including under- and overestimation of allergenic proteins as well as detection of allergens in very small 
quantities. More than 600 different food allergens are currently known. This extensive variety has led to the development of more robust, reliable and comparable methods such as mass spectrometry, which has a better resolution with respect to the limits of detection and quantification. A challenge that currently persists is the absence of commercial methods to test the presence of specific fish species in food which consequently makes the management of fish allergy, with respect to specific fish species, very challenging.

\section{Novel therapeutics}

Current management of fish allergy relies upon allergen avoidance; management plans for accidental exposure, and in many cases, provision of adrenaline auto injectors. However, advances in the understanding of the molecular characteristics of fish allergens $[24,41,73,100$, 101] are leading to novel approaches. Current approaches include targeting the calcium binding, muscle protein PV [102]. Recombinant hypoallergenic carp-PV is currently under investigation for potential subcutaneous (and potentially other routes) immunotherapy [103]. Sera from 26 proven fish allergic patients (by DBPCFC) were used to show 10-5,000 fold reduction in $\operatorname{lgE}$ binding to this hypoallergenic PV, while retaining immunogenicity [as confirmed in a murine model]. Currently, clinical trials are in progress and the efficacy of this hypoallergenic protein has yet to be established [104] (ClinicalTrials.gov identifier: NCT02017626).

There are currently no published reports of oral or sublingual fish sensitization trials. However, as oral and sublingual immunotherapy regimes for other food allergies such as cow's milk, egg and peanut are refined, with improved efficacy and long term tolerance; it is likely that oral fish immunotherapy, with modified allergen or with adjuvant will eventually be available.

\section{Conclusion}

The consequences of fish allergy for adults and children are significant, and immunotherapeutic approaches to induce desensitization or sustained tolerance to fish allergens are currently only 
364 in early phase development. PV has been demonstrated as the major allergenic protein in fish.

365 The high degree of PV amino acid sequence variability between different fish species and

366 lineages seems to be central to clinical sensitization. The molecular phylogenetic similarity

367 among beta-PVs of bony fish best explains the high allergenicity across species and groups and

368 low clinical cross-reactivity to the alpha-lineage of PV, present in most cartilaginous and ancient

369 fish species. Consequently the distance of amino acid sequence homology between different

370 PVs could be the ultimate indicator for clinical-cross-reactivity. A better understanding of the

371 molecular, immunological and biochemical characteristics of fish allergens is required to aid the

372 development of better clinical diagnostics and patient management, food processing

373 technologies, allergen detection methods as well as novel immunotherapeutics.

374

375 Acknowledgements:

376 TR is a full-time CFAR Scholar. AL and DC are holding an NHMRC Grant .

377

378 References:

379 1. Sharp, M.F. and A.L. Lopata, Fish Allergy: In Review. Clinical Reviews in Allergy \& Immunology, 380 2013:p.1-14.

381 2. Bugajska-Schretter, A., et al., Parvalbumin, a cross-reactive fish allergen, contains IgE-binding 382

3. Jiang, Y., J.D. Johnson, and J.A. Rall, Parvalbumin relaxes frog skeletal muscle when sarcoplasmic

4. Chard, P.S., et al., Calcium buffering properties of calbindin D28k and parvalbumin in rat sensory

5. Arif, S.H., A Ca2+-binding protein with numerous roles and uses: parvalbumin in molecular

6. Jeebhay, M.F., et al., Occupational seafood allergy: a review. Occup Environ Med, 2001. 58(9): p. 553-62.

393 7. Hajeb, P. and J. Selamat, A contemporary review of seafood allergy. Clin Rev Allergy Immunol, 2012. 42(3): p. 365-85.

This article is protected by copyright. All rights reserved 
8. Connett, G.J., et al., A Population-Based Study of Fish Allergy in the Philippines, Singapore and Thailand. International Archives of Allergy and Immunology, 2012. 159(4): p. 384-390.

9. Lao-araya, M. and M. Trakultivakorn, Prevalence of food allergy among preschool children in northern Thailand. Pediatr Int, 2012. 54(2): p. 238-43.

10. Thong, B.Y., et al., Anaphylaxis in adults referred to a clinical immunology/allergy centre in Singapore. Singapore Med J, 2005. 46(10): p. 529-34.

11. Thong, B.Y., et al., Immediate food hypersensitivity among adults attending a clinical immunology/allergy centre in Singapore. Singapore Med J, 2007. 48(3): p. 236-240.

12. Eggesb $\varnothing$, M., et al., Prevalence of parentally perceived adverse reactions to food in young children. Pediatric Allergy and Immunology, 1999. 10(2): p. 122-132.

13. Osterballe, M., et al., The Prevalence of food hypersensitivity in young adults. Pediatric Allergy and Immunology, 2009. 20(7): p. 686-692.

14. Burney, P.G., et al., The prevalence and distribution of food sensitization in European adults. Allergy, 2014. 69(3): p. 365-71.

15. Pascual, C.Y., et al., Fish allergy in childhood. Pediatric Allergy and Immunology, 2008. 19(7): p. 573-579.

16. Nwaru, B.I., et al., Prevalence of common food allergies in Europe: a systematic review and meta-analysis. Allergy, 2014.

17. Crespo, J.F., et al., Sensitization to Inhalant Allergens in Children Diagnosed with Food Hypersensitivity. Allergy and Asthma Proceedings, 1995. 16(2): p. 89-92.

18. Turner, P., et al., Seafood allergy in children: a descriptive study. Annals of Allergy, Asthma \& Immunology, 2011. 106(6): p. 494-501.

19. Ng, I.E., et al., Parental perceptions and dietary adherence in children with seafood allergy. Pediatric Allergy and Immunology, 2011. 22(7): p. 720-728.

20. Sicherer, S.H., A. Munoz-Furlong, and H.A. Sampson, Prevalence of seafood allergy in the United States determined by a random telephone survey. J Allergy Clin Immunol, 2004. 114(1): p. 15965.

21. Ben-Shoshan, M., et al., A population-based study on peanut, tree nut, fish, shellfish, and sesame allergy prevalence in Canada. Journal of Allergy and Clinical Immunology, 2010. 125(6): p. 13271335.

22. Vierk, K.A., et al., Prevalence of self-reported food allergy in American adults and use of food labels. Journal of Allergy and Clinical Immunology, 2007. 119(6): p. 1504-1510. 
427

428

429

430

431

432

433

434

435

436

437

438

439

440

23. Radauer, C., et al., Allergens are distributed into few protein families and possess a restricted number of biochemical functions. Journal of Allergy and Clinical Immunology. 121(4): p. 847852.e7.

24. Swoboda, I., et al., Recombinant Carp Parvalbumin, the Major Cross-Reactive Fish Allergen: $A$ Tool for Diagnosis and Therapy of Fish Allergy. The Journal of Immunology, 2002. 168(9): p. 4576-4584.

25. Roquet, F., et al., Crystal structure of the unique parvalbumin component from muscle of the leopard shark (Triakis semifasciata): The first $X$-ray study of an $\alpha$-parvalbumin. Journal of Molecular Biology, 1992. 223(3): p. 705-720.

26. Cai, Q.-F., et al., Purification and Characterization of Parvalbumins, the Major Allergens in Red Stingray (Dasyatis akajei). Journal of Agricultural and Food Chemistry, 2010. 58(24): p. 1296412969.

27. Kobayashi, A., et al., Comparison of allergenicity and allergens between fish white and dark muscles. Allergy, 2006. 61(3): p. 357-363.

28. Aas, K. and S. Elsayed, Physico-chemical properties and specific activity of a purified allergen (codfish). Dev Biol Stand., 1975. 29: p. 90-98.

29. Aas, K. and S.M. Elsayed, Characterization of a major allergen (cod). Effect of enzymic hydrolysis on the allergenic activity. J Allergy., 1969. 44(6): p. 333-343.

30. Chen, L., et al., Detecting Fish Parvalbumin with Commercial Mouse Monoclonal Anti-frog Parvalbumin IgG. Journal of Agricultural and Food Chemistry, 2006. 54(15): p. 5577-5582.

31. Bugajska-Schretter, A., et al., Purification, biochemical, and immunological characterisation of a major food allergen: different immunoglobulin E recognition of the apo- and calcium-bound forms of carp parvalbumin. Gut, 2000. 46(5): p. 661-9.

32. Untersmayr, E., et al., Mimotopes identify conformational epitopes on parvalbumin, the major fish allergen. Molecular Immunology, 2006. 43(9): p. 1454-1461.

33. Elsayed, S. and K. Aas, Isolation of purified allergens (cod) by isoelectric focusing. Int Arch Allergy Appl Immunol., 1971. 40(3): p. 428-438.

34. Elsayed S, A.J., Immunochemical analysis of cod fish allergen M: locations of the immunoglobulin binding sites as demonstrated by the native and synthetic peptides. Allergy, 1983. 38(7): p. 449459. 
35. Hemmens, V.J., et al., Common antigenic and allergenic determinants on codfish proteins detected with mouse monoclonal IgG and human IgE antibodies. Molecular Immunology, 1989. 26(5): p. 477-484.

36. Moraes, A.H., et al., Solution and high-pressure NMR studies of the structure, dynamics and stability of the cross-reactive allergenic cod parvalbumin Gad m 1. Proteins: Structure, Function, and Bioinformatics, 2014: p. n/a-n/a.

37. Ma, Y., et al., Comparison of natural and recombinant forms of the major fish allergen parvalbumin from cod and carp. Molecular Nutrition \& Food Research, 2008. 52(S2): p. S196S207.

38. Van Do, T., et al., Characterization of parvalbumin, the major allergen in Alaska pollack, and comparison with codfish Allergen M. Mol Immunol, 2005. 42(3): p. 345-53.

39. Van Do, T., et al., Allergy to fish parvalbumins: Studies on the cross-reactivity of allergens from 9 commonly consumed fish. Journal of Allergy and Clinical Immunology, 2005. 116(6): p. 13141320.

40. Bugajska-Schretter, A., et al., Purification, biochemical, and immunological characterisation of a major food allergen: different immunoglobulin E recognition of the apo- and calcium-bound forms of carp parvalbumin. Gut, 2000. 46(5): p. 661-669.

41. Swoboda, I., et al., A Recombinant Hypoallergenic Parvalbumin Mutant for Immunotherapy of IgE-Mediated Fish Allergy. The Journal of Immunology, 2007. 178(10): p. 6290-6296.

42. Liu, G.-M., et al., Purification and characterization of parvalbumins from silver carp (Hypophthalmichthy molitrix). Journal of the Science of Food and Agriculture, 2010. 90(6): p. 1034-1040.

43. Sharp, M.F., et al., Immunological cross-reactivity between four distant parvalbumins-Impact on allergen detection and diagnostics. Mol Immunol, 2015. 63(2): p. 437-48.

44. Perez-Gordo, M., et al., Epitope Mapping of Atlantic Salmon Major Allergen by Peptide Microarray Immunoassay. International Archives of Allergy and Immunology, 2012. 157(1): p. $31-40$.

45. Shimizu, Y., et al., Major Allergen and Its IgE Cross-Reactivity among Salmonid Fish Roe Allergy. Journal of Agricultural and Food Chemistry, 2009. 57(6): p. 2314-2319.

46. Harumi Koyama, M.K., Makiko Kawamura, Reiko Tokuda, Yasuto Kondo, Ikuya Tsuge, Kazue Yamada, Toshitaka Yasuda and Atsuo Urisu, Grades of 43 Fish Species in Japan Based on IgEbinding Activity. Allergology International, 2006. 55(3): p. 311-316. 
47. Van, D., et al., Expression and Analysis of Recombinant Salmon Parvalbumin, the Major Allergen in Atlantic Salmon (Salmo salar). Scandinavian Journal of Immunology, 1999. 50(6): p. 619-625.

48. Sharp, M.F., et al., Differential IgE binding to isoallergens from Asian seabass (Lates calcarifer) in children and adults. Molecular Immunology, 2014. 62(1): p. 77-85.

49. $\mathrm{Xu}, \mathrm{Y} . \mathrm{X}$., et al., Characterization of two parvalbumin genes and their association with growth traits in Asian seabass (Lates calcarifer). Animal Genetics, 2006. 37(3): p. 266-268.

50. Heffron, J.K. and T.S. Moerland, Parvalbumin characterization from the euryhaline stingray Dasyatis sabina. Comparative Biochemistry and Physiology Part A: Molecular \& Integrative Physiology, 2008. 150(3): p. 339-346.

51. Thatcher, D.R. and J.-F. Pechere, The Amino-Acid Sequence of the Major Parvalbumin from Thornback-Ray Muscle. European Journal of Biochemistry, 1977. 75(1): p. 121-132.

52. Friedberg, F., Parvalbumin Isoforms in Zebrafish. Molecular Biology Reports, 2005. 32(3): p. 167175.

53. Calderon-Rodriguez, S., et al., Tolerability to dogfish in children with fish allergy. Allergologia et immunopathologia, 2015.

54. San-Juan, S., et al., Occupational asthma caused by shark cartilage dust. Journal of Allergy and Clinical Immunology, 2004. 114(5): p. 1227-1228.

55. Ortega, H.G., et al., Fatal asthma from powdering shark cartilage and review of fatal occupational asthma literature. American Journal of Industrial Medicine, 2002. 42(1): p. 50-54.

56. Jenkins, J.A., H. Breiteneder, and E.N.C. Mills, Evolutionary distance from human homologs reflects allergenicity of animal food proteins. Journal of Allergy and Clinical Immunology, 2007. 120(6): p. 1399-1405.

57. Perez-Gordo, M., et al., Epitope mapping of the major allergen from Atlantic cod in Spanish population reveals different IgE-binding patterns. Mol Nutr Food Res, 2013. 57(7): p. 1283-90.

58. Yoshida, S., A. Ichimura, and K. Shiomi, Elucidation of a major IgE epitope of Pacific mackerel parvalbumin. Food Chemistry, 2008(111): p. 857-861.

59. Kobayashi, A., et al., IgE-binding epitopes of variouffish parvalbumins exist in a stereoscopic conformation maintained by Ca<sup $>2+</$ sup $>$ binding. Allergology International, 2016. 65(3): p. $345-348$.

60. Yamaguchi, J., et al., A Case of occupational contact urticaria and oral allergy syndrome due to seafood. Jpn. J. Allergol., 2007. 56(1): p. 49-53. 
61. Hamada, Y., Y. Nagashima, and K. Shiomi, Identification of Collagen as a New Fish Allergen. Bioscience, Biotechnology, and Biochemistry, 2001. 65(2): p. 285-291.

62. Sakaguchi, M., et al., IgE antibody to fish gelatin (type I collagen) in patients with fish allergy. J Allergy Clin Immunol, 2000. 106(3): p. 579-84.

63. Kuehn, A., et al., Identification of enolases and aldolases as important fish allergens in cod, salmon and tuna: component resolved diagnosis using parvalbumin and the new allergens. Clinical \& Experimental Allergy, 2013. 43(7): p. 811-822.

64. Kuehn, A., C. Hilger, and F. Hentges, Anaphylaxis provoked by ingestion of marshmallows containing fish gelatin. Journal of Allergy and Clinical Immunology, 2009. 123(3): p. 708-709.

65. Perez-Gordo, M., et al., Identification of vitellogenin as an allergen in Beluga caviar allergy. Allergy, 2008. 63(4): p. 479-480.

66. Hamada, Y., Y. Nagashima, and K. Shiomi, Identification of collagen as a new fish allergen. Bioscience Biotechnology Biochemistry, 2001. 65(2): p. 285-91.

67. Kobayashi, Y., et al., Allergy to fish collagen: Thermostability of collagen and IgE reactivity of patients\&apos; sera with extracts of 11 species of bony and cartilaginous fish. Allergology International, 2016. 65(4): p. 450-458.

68. Kobayashi, Y., et al., Study of the cross-reactivity of fish allergens based on a questionnaire and blood testing. Allergology International, 2016. 65(3): p. 272-279.

69. Yamada, S., H. Nolte, and E. Zychlinsky, Identification and characterization of allergens in two species of tuna fish. Annals of Allergy, Asthma \& Immunology, 1999. 82(4): p. 395-400.

70. Nieuwenhuizen, N., et al., Exposure to the fish parasite Anisakis causes allergic airway hyperreactivity and dermatitis. Journal of Allergy and Clinical Immunology, 2006. 117(5): p. 1098-105.

71. Rodriguez-Perez, R., et al., Cloning and expression of a biologically active Anisakis simplex allergen Ani s 1 in the yeast Pichia pastoris. Molecular and Biochemical Parasitology, 2007. 154(1): p. 115-118.

72. Audicana, M.T. and M.W. Kennedy, Anisakis simplex: from Obscure Infectious Worm to Inducer of Immune Hypersensitivity. Clinical Microbiology Reviews, 2008. 21(2): p. 360-379.

73. Lopata, A.L. and S.B. Lehrer, New insights into seafood allergy. Current Opinion in Allergy and Clinical Immunology, 2009. 9(3): p. 270-277.

74. Baird, F.J., et al., Foodborne anisakiasis and allergy. Molecular and cellular probes. 28(4): p. 167174. 
552 75. Nieuwenhuizen, N., et al., Exposure to the fish parasite Anisakis causes allergic airway hyperreactivity and dermatitis. Journal of Allergy and Clinical Immunology, 2006. 117(5): p.

76. Kirstein, F., et al., Anisakis pegreffii-Induced Airway Hyperresponsiveness Is Mediated by Gamma

77. Untersmayr, E., et al., Incomplete digestion of codfish represents a risk factor for anaphylaxis in patients with allergy. Journal of Allergy and Clinical Immunology, 2007. 119(3): p. 711-717.

78. Beale, J.E., M.F. Jeebhay, and A.L. Lopata, Characterisation of purified parvalbumin from five fish species and nucleotide sequencing of this major allergen from Pacific pilchard, Sardinops sagax. Molecular Immunology, 2009. 46(15): p. 2985-2993.

79. Gonzàlez-Mendiola, R., et al., Auriculotemporal syndrome: differential diagnostic of food allergy. Allergy, 2003. 58(12): p. 1315-1315.

80. Griesmeier, U., et al., Expression levels of parvalbumins determine allergenicity of fish species. Allergy, 2010. 65(2): p. 191-198.

84. Lopata, A.L. and M.F. Jeebhay, Airborne seafood allergens as a cause of occupational allergy and

86. Jeebhay, M.F., et al., Occupational allergy and asthma among salt water fish processing workers. American Journal of Industrial Medicine, 2008. 51(12): p. 899-910.

88. Douglas, J.D., et al., Occupational asthma caused by automated salmon processing. The Lancet, 1995. 346(8977): p. 737-740. 
89. Lopata, A. and M. Jeebhay, Airborne Seafood Allergens as a Cause of Occupational Allergy and Asthma. Current Allergy and Asthma Reports, 2013. 13(3): p. 288-297.

90. Lopata, A.L., et al., Detection of Fish Antigens Aerosolized during Fish Processing Using Newly Developed Immunoassays. International Archives of Allergy and Immunology, 2005. 138(1): p. 21-28.

91. Jeebhay, M.F., et al., Environmental Exposure Characterization of Fish Processing Workers. Annals of Occupational Hygiene, 2005. 49(5): p. 423-437.

92. Jeebhay, M.F., T.G. Robins, and A.L. Lopata, World at work: Fish processing workers. Occupational and Environmental Medicine, 2004. 61(5): p. 471-474.

93. Rodriguez, J., et al., Occupational asthma caused by fish inhalation. Allergy, 1997. 52(8): p. 8669.

94. Taylor, A.V., et al., Detection and quantitation of raw fish aeroallergens from an open-air fish market. Journal of Allergy and Clinical Immunology, 2000. 105(1, Part 1): p. 166-169.

95. Van Ree, R., et al., Possible induction of food allergy during mite immunotherapy. Allergy, 1996. 51(2): p. 108-13.

96. Ballmer-Weber, B.K., et al., How much is too much? Threshold dose distributions for 5 food allergens. Journal of Allergy and Clinical Immunology, 2015. 135(4): p. 964-971.

97. Taylor, S.L., et al., Factors affecting the determination of threshold doses for allergenic foods: How much is too much? Journal of Allergy and Clinical Immunology, 2002. 109(1): p. 24-30.

98. Zinn, C., et al., The spectrum of allergy to South African bony fish (Teleosti). Evaluation by double-blind, placebo-controlled challenge. South African Medical Journal, 1997. 87(2): p. 146152.

99. Koeberl, M., D. Clarke, and A.L. Lopata, Next Generation of Food Allergen Quantification Using Mass Spectrometric Systems. Journal of Proteome Research, 2014. 13(8): p. 3499-3509.

100. Burks, W., S.B. Lehrer, and G.A. Bannon, New approaches for treatment of peanut allergy: chances for a cure. Clin Rev Allergy Immunol, 2004. 27(3): p. 191-6.

101. Nieuwenhuizen, N.E. and A.L. Lopata, Fighting Food Allergy: Current Approaches. Annals of the New York Academy of Sciences, 2005. 1056(1): p. 30-45.

102. Buonomo, A., E. Nucera, and D. Schiavino, Doctor, can I desensitize my food-allergic child using directly the allergenic molecules? Current opinion in allergy and clinical immunology, 2016. 16(3): p. 278-283. 
615

616

617

618

619

620

621

622

623

624

625

626

627

628

629

630

631

632

633

634

635

636

637

638

639

640

641

642

643

644

103. Zuidmeer-Jongejan, L., et al., FAST: towards safe and effective subcutaneous immunotherapy of persistent life-threatening food allergies. Clinical and Translational Allergy, 2012. 2(1): p. 5.

104. Zuidmeer-Jongejan, L., et al., Development of a Hypoallergenic Recombinant Parvalbumin for First-in-Man Subcutaneous Immunotherapy of Fish Allergy. International Archives of Allergy and Immunology, 2015. 166(1): p. 41-51.

105. Chen, J., et al., Prevalence of food allergy in children under 2 years of age in three cities in China. Zhonghua Er Ke Za Zhi, 2012. 50(1): p. 5-9.

106. Leung, T.F., et al., Parent-reported adverse food reactions in Hong Kong Chinese pre-schoolers: epidemiology, clinical spectrum and risk factors. Pediatric Allergy and Immunology, 2009. 20(4): p. 339-346.

107. Kim, J., et al., The incidence and risk factors of immediate type food allergy during the first year of life in Korean infants: a birth cohort study. Pediatric Allergy and Immunology, 2011. 22(7): p. 715-719.

108. Wu, T.C., et al., Prevalence of food allergy in Taiwan: a questionnaire-based survey. Internal Medicine Journal, 2012. 42(12): p. 1310-1315.

109. Osterballe, M., et al., The prevalence of food hypersensitivity in an unselected population of children and adults. Pediatric Allergy and Immunology, 2005. 16(7): p. 567-573.

110. Kull, I., et al., Fish consumption during the first year of life and development of allergic diseases during childhood. Allergy, 2006. 61(8): p. 1009-1015.

111. Venter, C., et al., Original article: Prevalence and cumulative incidence of food hypersensitivity in the first 3 years of life. Allergy, 2008. 63(3): p. 354-359.

112. Pereira, B., et al., Prevalence of sensitization to food allergens, reported adverse reaction to foods, food avoidance, and food hypersensitivity among teenagers. Journal of Allergy and Clinical Immunology, 2005. 116(4): p. 884-892.

113. Swoboda, I., et al., Recombinant fish parvalbumins: Candidates for diagnosis and treatment of fish allergy. Allergy, 2002. 57: p. 94-96.

114. Gupta, R.S., et al., The Prevalence, Severity, and Distribution of Childhood Food Allergy in the United States. Pediatrics, 2011. 128(1): p. e9-e17.

115. Jauregui-Adell, J. and J.F. Pechere, Parvalbumins from coelacanth muscle. III. Amino acid sequence of the major component. Biochimica et Biophysica Acta, 1978. 536(1): p. 275-282. 
645

646

647

648

649

650

651

652

653

654

655

656

657

658

659

660

661

662

663

664

665

666

667

668

669

670

671

116. Elsayed, S. and J. Apold, Immunochemical analysis of cod fish allergen M: locations of the immunoglobulin binding sites as demonstrated by the native and synthetic peptides. Allergy, 1983. 38(7): p. 449-59.

117. Lindstrom, C.D., et al., Cloning of two distinct CDNAs encoding parvalbumin, the major allergen of Atlantic salmon (Salmo salar). Scandinavian Journal of Immunology, 1996. 44(4): p. 335-44.

118. Van Do, T., et al., The major allergen (parvalbumin) of codfish is encoded by at least two isotypic genes: cDNA cloning, expression and antibody binding of the recombinant allergens. Molecular Immunology, 2003. 39(10): p. 595-602.

119. Hamada, Y., et al., Purification, reactivity with IgE and CDNA cloning of parvalbumin as the major allergen of mackerels. Food and Chemical Toxicology, 2003. 41(8): p. 1149-1156.

120. Van Do, T., et al., Characterization of parvalbumin, the major allergen in Alaska pollack, and comparison with codfish allergen M. Molecular Immunology, 2005. 42(3): p. 345-353.

121. Thatcher, D.R. and J.F. Pechere, The Amino-Acid Sequence of the Major Parvalbumin from Thornback-Ray Muscle. European Journal of Biochemistry, 1977. 75(1): p. 121-132.

122. Conlon, J.M., et al., Purification and characterization of urotensin II and parvalbumin from an elasmobranch fish, Scyliorhinus canicula (common dogfish). 1992(0028-3835 (Print)).

123. Venkatesh, B., et al., Elephant shark genome provides unique insights into gnathostome evolution. Nature, 2014. 505(7482): p. 174-179.
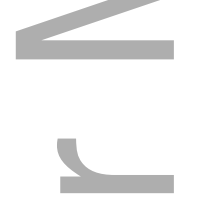

$\longrightarrow$
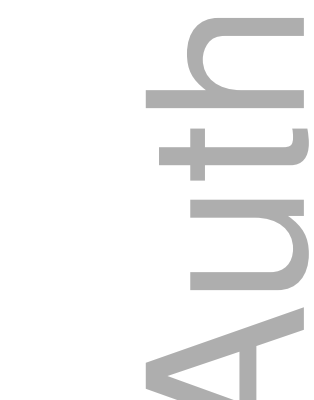

Figure Legends:

This article is protected by copyright. All rights reserved 
672 cartilaginous fish species (Leopard shark, Thornback ray, Australian ghost shark) generated in 673 Clustal Omega. Highly conserved amino acids are shaded dark blue. Note: $\mathrm{Ca}^{2+}$ binding sites are

674 boxed in red. (B) Conservation analysis shows degree of conservation of amino acids among the 675 various different fish. The scores range from 1-10, 1 (dark brown) being least conserved amino 676 acid to 10 (yellow) being 100\% conservation across all the fish species analyzed.

677

Figure 2: Unrooted neighbor joining dendrogram showing evolutionary relationships of parvalbumin from vertebrates constructed in MEGA5. (A) $\alpha$-parvalbumins. (B) $\beta$-parvalbumins. The tree is drawn to scale. The evolutionary distances were computed using the Poisson correction method. Amino acid sequences were obtained from UniProt.

682

683 Figure 3: A) Amino acid sequence alignment of Atlantic cod (UniprotKB Accession number: 684 A51874), Baltic cod (UniprotKB Accession number: P02622), common carp (UniprotKB Accession 685 number: EOWD92), Atlantic salmon (UniprotKB Accession number: B5DH15) and chub mackerel 686 (UniprotKB Accession number: P59747) showing known IgE-binding regions coloured in yellow, 687 orange, blue, purple and green. (B) Space filling parvalbumin models of common carp, Chub 688 mackerel, Atlantic salmon, Atlantic cod and Baltic cod. The corresponding coloured IgE binding 689 epitopes from (A) are depicted on the space filling models.

690
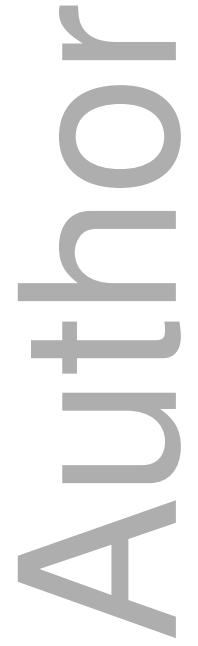

This article is protected by copyright. All rights reserved 
693 parents or self-reported. Patient history: symptoms occurring in less than 2 hours. SPT: skin prick test. OFC: oral food challenge.

694 DBPCFC: double blind placebo controlled food challenge. FE: Food elimination.

\begin{tabular}{|c|c|c|c|c|c|}
\hline Country & $\begin{array}{c}\text { Age of } \\
\text { individuals }\end{array}$ & $\begin{array}{l}\text { Number of } \\
\text { individuals }\end{array}$ & $\begin{array}{c}\text { Sensitization } \\
\text { to fish (\%) }\end{array}$ & Methods of confirmation & References \\
\hline \multicolumn{6}{|c|}{ ASIA } \\
\hline China & $0-2$ & 1,604 & 0.21 & Report, SPT, FE, DBPCFC & {$[105]$} \\
\hline Hong Kong & $2-7$ & 3,677 & 0.25 & Report, Physician-diagnosis & {$[106]$} \\
\hline & $<1$ & 1,177 & - & $\begin{array}{c}\text { Telephone interview, patient } \\
\text { history }\end{array}$ & [107] \\
\hline Philippines & $14-16$ & 13,989 & 2.29 & Patient history & [8] \\
\hline Singapore & $14-16$ & 9,570 & 0.26 & Patient history & [9] \\
\hline Taiw & $\begin{array}{c}<3 \\
4-18 \\
\text { Adults }\end{array}$ & $\begin{array}{c}813 \\
15,169 \\
11026\end{array}$ & $\begin{array}{l}0.49 \\
0.49 \\
117\end{array}$ & $\begin{array}{c}\text { Patient history, SPT, Serum IgE } \\
\text { levels, FC }\end{array}$ & [108] \\
\hline r & $\begin{array}{c}3-7 \\
14-16\end{array}$ & $\begin{array}{c}656 \\
2,536\end{array}$ & $\begin{array}{l}0.22 \\
0.29\end{array}$ & $\begin{array}{c}\text { Report, SPT, OFC, Serum IgE levels, } \\
\text { patient history }\end{array}$ & $\begin{array}{l}{[9]} \\
{[8]}\end{array}$ \\
\hline
\end{tabular}

This article is protected by copyright. All rights reserved 


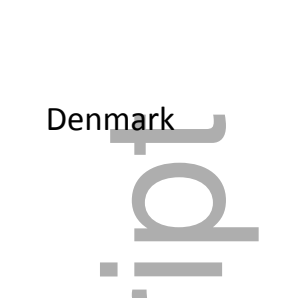

Norway $\quad 0-2$

Sweden 0-4

(1) 0-3

UK

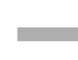

(1)

0

South Africa
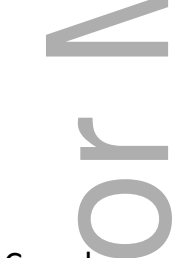

Canada
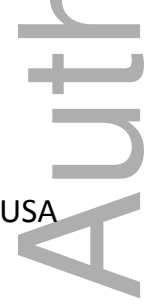

\section{3}

Adults

22

486

936

1,282

3623

2,614

891

775

757

15

Adults

594

Adults

0-2

6-10

14-18

0-17

18-61

9,667

9,911

10,514

2,707
0.2

0.1

3.0

0.69

-

1.16

1.19

\section{AFRICA}

Report, SPT, Serum IgE levels,

7.0 determination of omega-3

fatty acids, Spirometry, MCT

\section{NORTH AMERICA}

Telephone interview, Report,

0.10

Patient history, Physician-

diagnosis, SPT, IgE levels, OFC

$5,429 \quad 0.30$

0.50

0.60

Report, Physician-diagnosis,

0.22

SPT, Serum IgE levels, OFC

[20]

[20] 


\section{OCEANIA}

\begin{tabular}{|c|c|c|c|c|c|}
\hline \multicolumn{6}{|c|}{ OCEANIA } \\
\hline & $2-5$ & 154 & 62 & Report. SPT OFC & [18] \\
\hline Austranlia & $3-8$ & 94 & - & Report, SPT, OFC & [19] \\
\hline
\end{tabular}

695

696

697 Table 2: Selection of allergenic parvalbumins in muscle-tissue of bony and cartilaginous fish, listed in ascending order of 698 discovery. Common and scientific names of species, their molecular weight in kDa and the isoform lineage have been listed. For 699 cartilaginous fish (A) or (B) identifies the species belonging to the Elasmobranchii (A) or Holocephali (B), respectively.

\begin{tabular}{|c|c|c|c|c|c|}
\hline Common Name & Scientific Name & $\begin{array}{l}\text { Isoform } \\
\text { Lineage }\end{array}$ & $\begin{array}{l}\text { Isoelectric } \\
\text { Point }\end{array}$ & $\begin{array}{c}\text { Molecular Weight } \\
\text { (kDa) }\end{array}$ & References \\
\hline $\begin{array}{c}\text { West Indian Ocean } \\
\text { coelacanth }\end{array}$ & Latimeria chalumnae & $\alpha$ or $\beta$ & $4.93 \& 4.68$ & $12.2 \& 11.732$ & [115] \\
\hline Baltic C & Gadus callarias & $\beta$ & 4.37 & 12.1 & {$[116]$} \\
\hline Atlantic salmon & Salmo salar & $\beta$ & 4.95 & 11.9 & {$[117]$} \\
\hline Carp & Cyprinus carpio & $\beta$ & 4.25 & 11.5 & {$[113]$} \\
\hline Atlantic cod & Gadus morhua & $\beta$ & 4.56 & 11.5 & [118] \\
\hline Chub mackerel & Scomber japonicus & $\beta$ & 4.64 & 11.5 & [119] \\
\hline Alaska pollock & Theragra chalcogramma & $\beta$ & 4.60 & 11.5 & {$[120]$} \\
\hline Barramundi & Lates calcarifer & $\beta 1, \beta 2$ & 4.48 & 11.6 & [49] \\
\hline
\end{tabular}




\begin{tabular}{|c|c|c|c|c|c|}
\hline Pacific pilchard & Sardinops sagax & $\beta$ & 6.07 & 11.9 & [78] \\
\hline Whiff & $\begin{array}{c}\text { Lepidorhombus } \\
\text { whiffiagonis }\end{array}$ & $\beta$ & 4.50 & 11.7 & [80] \\
\hline Swordfish & Xiphias gladius & $\beta$ & 4.43 & 11.5 & {$[80]$} \\
\hline \multicolumn{6}{|c|}{ CHONDRICHTHYES (CARTILAGINOUS FISH) } \\
\hline Thornback ray (A) & Raja clavata & $\alpha \operatorname{or} \beta$ & 4.45 & 11.8 & [121] \\
\hline Leopard shark (A) & Triakis semifasciata & $\alpha$ & 5.14 & 12 & {$[25]$} \\
\hline Common dogfish (A) & Scyliothinus canicula & - & - & - & [122] \\
\hline Atlantic stingray (A) & Dasyatis sabina & $\alpha \operatorname{or} \beta$ & $4.95 \& 5.02$ & $12.2 \& 12$ & [50] \\
\hline Red stingray (A) & Dasyatis akajei & $\alpha \operatorname{or} \beta$ & $\sim 5$ & $12.3 \& 12$ & {$[26]$} \\
\hline $\begin{array}{c}\text { Australian ghost } \\
\text { shark (B) }\end{array}$ & Callorhinchus milii & $\alpha$ & 5.04 & 12.1 & [123] \\
\hline
\end{tabular}

700

701

702

703

704

705

706

707

708

This article is protected by copyright. All rights reserved 
711 Table 3: Comparison of amino acid sequence identities of fish alpha- and some beta-parvalbumin calculated using ClustalW. The fish species have been grouped into Chondrichthyes (red) and Osteichthyes (blue) (Values are shown in percentage). Sequences

713 obtained from UniProt.

714

715

\begin{tabular}{|c|c|c|c|c|c|c|c|c|c|c|c|}
\hline 01 & $\begin{array}{l}\text { Leopard } \\
\text { shark } \alpha\end{array}$ & $\begin{array}{c}\text { Thornback } \\
\text { ray } \alpha\end{array}$ & $\begin{array}{c}\text { Australian } \\
\text { ghost shark } \\
\alpha\end{array}$ & $\begin{array}{l}\text { Baltic } \\
\operatorname{cod} \beta\end{array}$ & $\begin{array}{c}\text { Common } \\
\operatorname{carp} \beta\end{array}$ & $\begin{array}{c}\text { Atlantic } \\
\text { salmon } \\
\alpha\end{array}$ & $\begin{array}{c}\text { Atlantic } \\
\text { salmon } \\
\beta\end{array}$ & $\begin{array}{c}\text { Chub } \\
\text { mackerel } \\
\beta\end{array}$ & $\begin{array}{c}\text { West } \\
\text { Indian } \\
\text { Ocean } \\
\text { coelacanth } \\
\alpha\end{array}$ & $\begin{array}{c}\text { West } \\
\text { Indian } \\
\text { Ocean } \\
\text { coelacanth } \\
\beta\end{array}$ & $\begin{array}{c}\text { Human } \\
\alpha\end{array}$ \\
\hline $\begin{array}{l}\text { Leopard shark } \alpha \\
\text { Thornback ray } \alpha\end{array}$ & $\begin{array}{l}100 \\
49\end{array}$ & 100 & & & & & & & & & \\
\hline $\begin{array}{l}\text { Australian ghost } \\
\text { shark } \alpha\end{array}$ & 46 & 48 & 100 & & & & & & & & \\
\hline Baltic $\operatorname{cod} \beta$ & 46 & 43 & 47 & 100 & & & & & & & \\
\hline Common carp $\beta$ & 50 & 51 & 56 & 66 & 100 & & & & & & \\
\hline Atlantic salmon $\alpha$ & 55 & 49 & 62 & 54 & 61 & 100 & & & & & \\
\hline Atlantic salmon $\beta$ & 48 & 46 & 49 & 51 & 70 & 60 & 100 & & & & \\
\hline Chubb mackerel $\beta$ & 52 & 56 & 52 & 61 & 79 & 57 & 64 & 100 & & & \\
\hline $\begin{array}{l}\text { West Indian Ocean } \\
\text { coelacanth } \alpha\end{array}$ & 62 & 50 & 58 & 50 & 57 & 59 & 48 & 58 & 100 & & \\
\hline $\begin{array}{l}\text { West Indian Ocean } \\
\text { coelacanth } \beta\end{array}$ & 47 & 55 & 53 & 54 & 70 & 49 & 58 & 63 & 53 & 100 & \\
\hline Human $\alpha$ & 58 & 47 & 67 & 49 & 58 & 67 & 50 & 51 & 57 & 51 & 100 \\
\hline
\end{tabular}




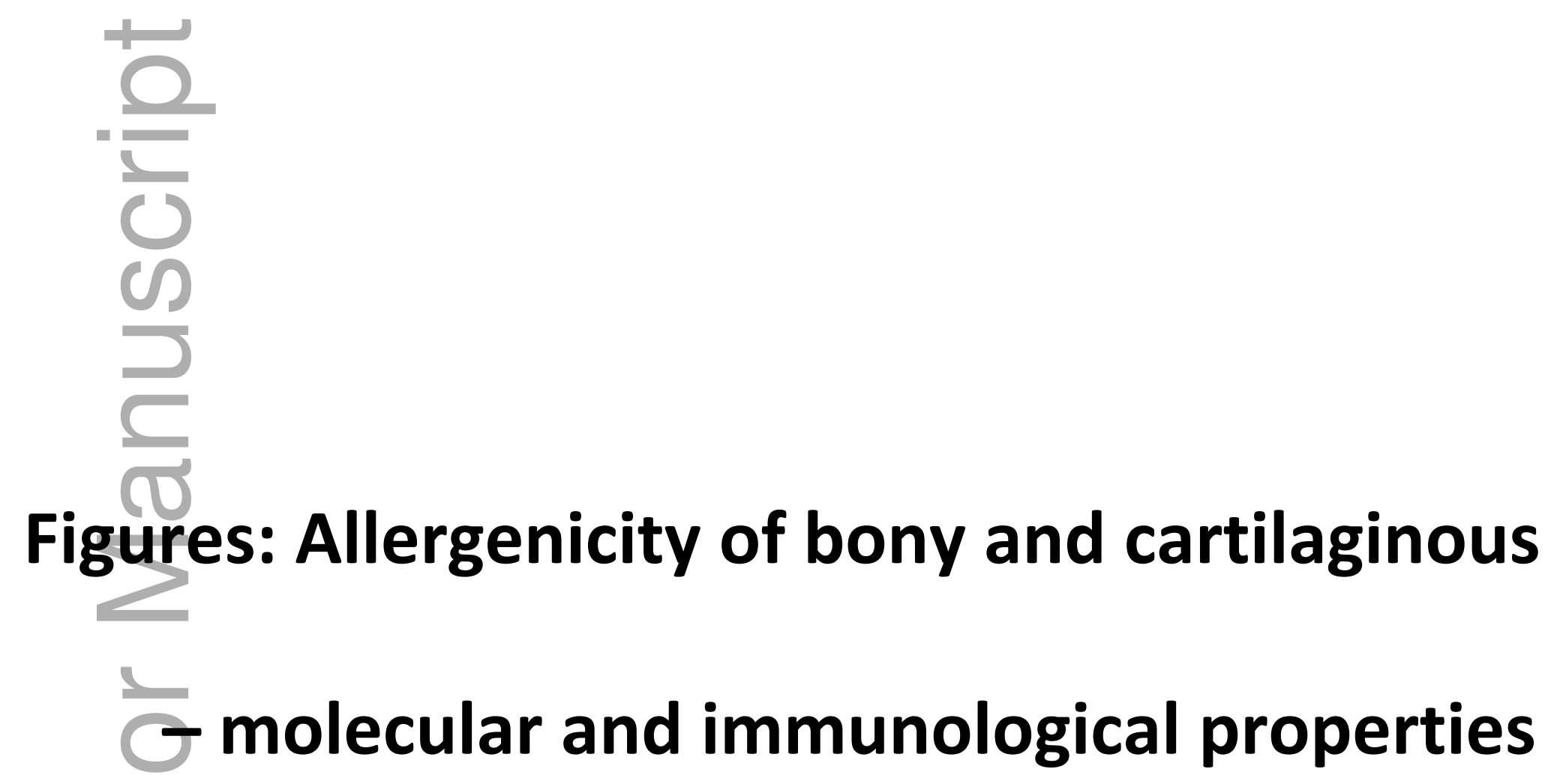




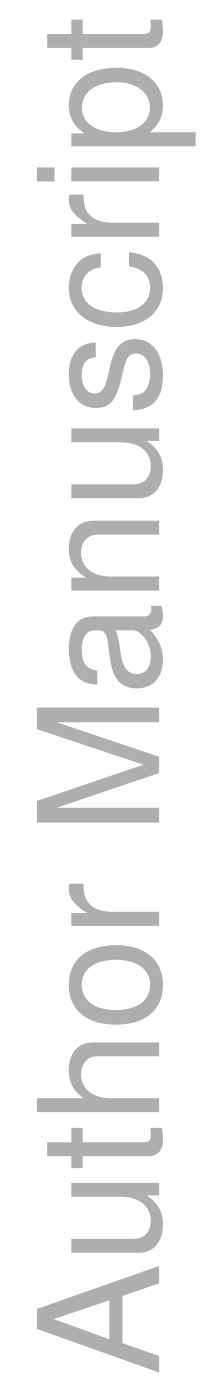

This article is protected by copyright. All rights reserved 


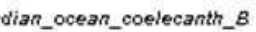

Thomback_ray

Leopard_shack

West_fodian_ocean_coelecanth_A

Elephant_shark

Atlantic_salmon_A

$10 \quad 20$

2030

50

70

80

90

100

110

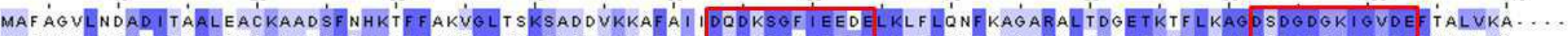
MAFASVIKDAE TAALDGCKAAGSFDHKKFFKACGLSGKSADEVKKAFAI DODKSGYIEEEFLKLFL QNFKAGARAL SDAETKAFLKAGDSDGDGKIOUDEFAAMIKG . . . MACAHLCKEAD IKTALEACKAADTFSFKTFFHTI GFASKSADDVKKAFKVIDQDASGFI EVEELKLFLONFCPKARELTDAETKAFLKAQDADGDGMIGIDEFAVLVKO. . AFKOIL SNADIKA AVAKL AAADVTAALEGCKADDSFNHKVEFOKT GLAKKSNEELEAIFKILDODKSOFI EDEELELFIONF SAGARTITKTETETFLKAGDSDGDGKIGVDEFOKLVKA...

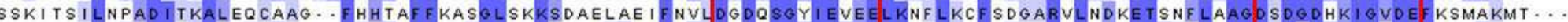
.PMTKVLKADD INKA I SAF KDPGTFDYKRFF HLVGLKGKT DAQVKEVFE I LDKDQSGF IEEEELKGVLKGFSAHGRDLNDTETKALLAAGDSDHDGKIOADEFAKMVAQA... TKKMSE I LKAED I DKALNTFKEAGSFDHHKFFNLVGLKGKPDDTLKEVFGILDQDKSGYIEEEELKFVLKGFAAGGRELTANETKALLKAGDQDGDDKIGVDEF TNLVKAA... MSINKILSAAD I TKALGEFKGADSFDHKKFFHMIGLKKKNAKDVEAVFYILDKDKSOFIEEDELKSVLKCFAPEGRDLSEKETKDLLTAGDEDGDGKIOVSEF IQLVANS. . . MAMNSILNAAD IKKALDAF AAADSFDHKKFFEMVGLKAKSAEDVKKAELVLDADASGFIEEEELKFVLKGEASDGRDLTDKETKAFLNEADKDGDGMIGIDEFVALVHE... .

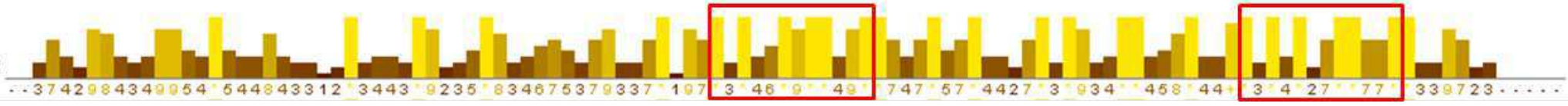

B

$$
\text { Consenvation }
$$

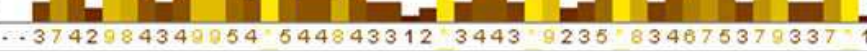

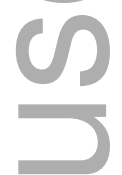

Figure 1

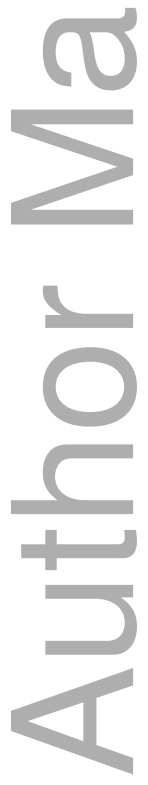



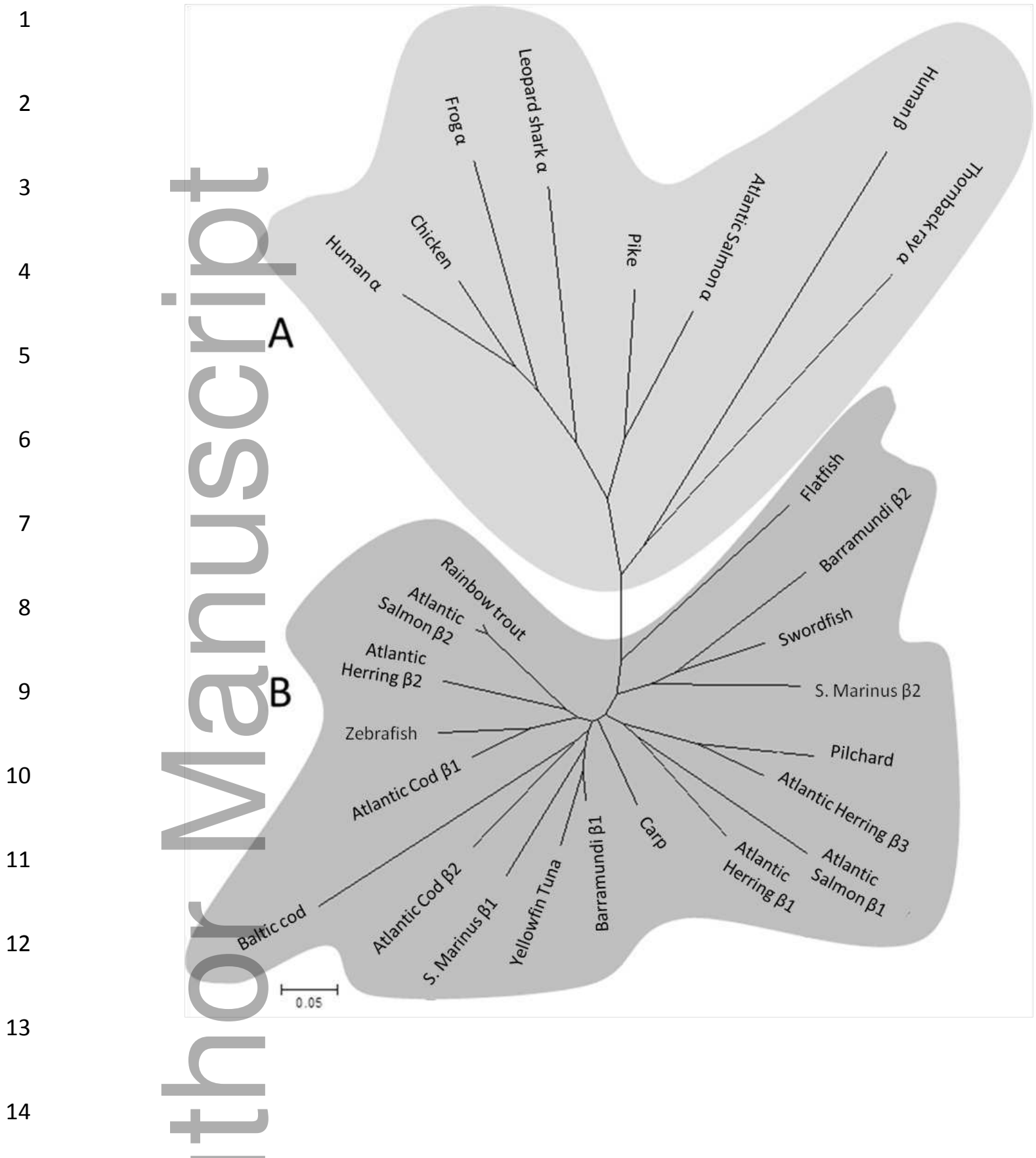

15 Figure 2 
MAFASVLKDAEVTAALDGCKAAGSFDHKKFFKACGLSGKSTDEVKKAFAIIDQDKSGFIE At lantic_salmon carp

At lantic_cod

20

Baltic_cod

21

Chub_mackere1 MACAHLCKEADIKTALEACKAADTFSFKTFFHTIGFASKSADDVKKAFKVIDQDASGFIE MAFAGVLNDADITAALEACKAADSFNHKTFFAKVGLTSKSADDVKKAFAIIDQDKSGFIE MAFAGILNDADITAALAACKAEGSFDHKAFFTKVGLAAKSPADIKKVFEIIDQDKSDFVE -AFKGILSNADIKAAEAACFKEGSFDEDGFYAKVGLDAFSADELKKLFKIADEDKEGFIE At lantic_salmon

EEELKLFLQNFKAGARALSDAETKAFLKAGDSDGDGKIGIDEFAAMIKG At 7 antic_cod Baltic_cod VEEKLFLQNFCPKAREL TDAETKAFLKAGDADGDGMIGIDEFAVLVKQ EDELKLFLQNFKAGARALTDGETKTFLKAGDSDGDGKIGVDEFTALVKA EDELKLFLQNFSAGARALSDAETKVFLKAGDSDGDGKIGVDEFGAMIKA EDELKLFLIAFAADLRALTDAETKAFLKAGDSDGDGKIGVDEFGALVDKWGAKG

22

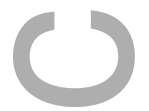

23

24

25

26

27

B<smiles>c1ccc2ccccc2c1</smiles>

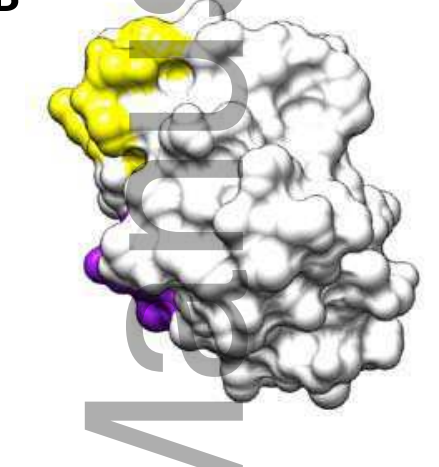

Carp

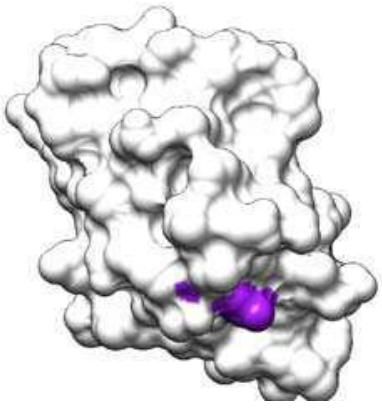

Chub mackerel

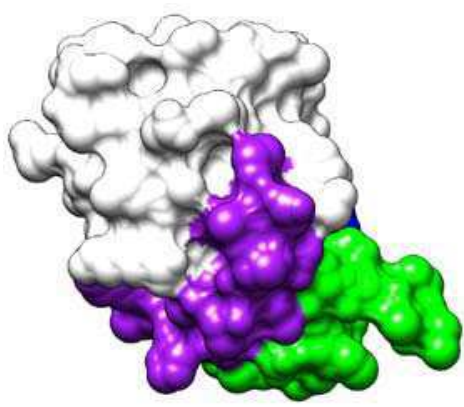

Atlantic salmon

28

29

30

31
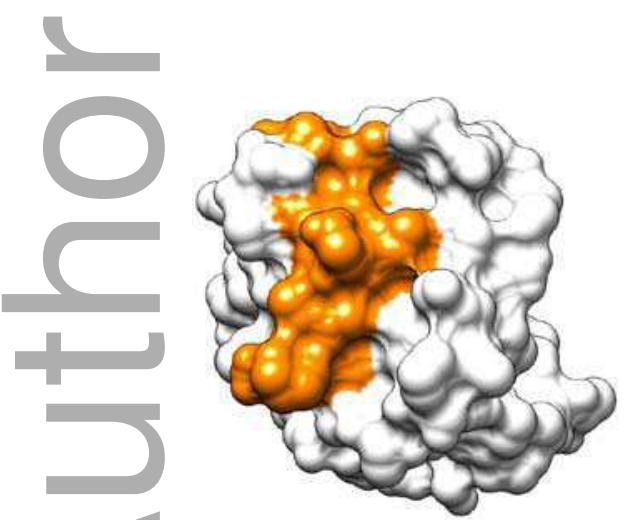

32

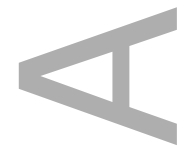

Atlantic cod

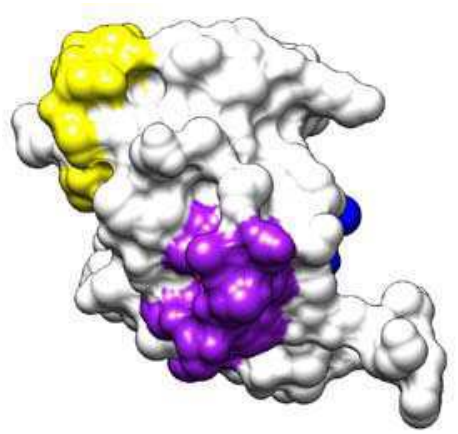

Baltic cod 


\section{University Library}

\section{- M M N E R VA A gateway to Melbourne's research publications}

Minerva Access is the Institutional Repository of The University of Melbourne

Author/s:

Stephen, JN;Sharp, MF;Ruethers, T;Taki, A;Campbell, DE;Lopata, AL

Title:

Allergenicity of bony and cartilaginous fish - molecular and immunological properties

Date:

2017-03-01

Citation:

Stephen, J. N., Sharp, M. F., Ruethers, T., Taki, A., Campbell, D. E. \& Lopata, A. L. (2017).

Allergenicity of bony and cartilaginous fish - molecular and immunological properties.

CLINICAL AND EXPERIMENTAL ALLERGY, 47 (3), pp.300-312. https://doi.org/10.1111/ cea.12892.

Persistent Link:

http://hdl.handle.net/11343/292433 